\title{
A EDIFICAÇÃO DO CENTRO DE EDUCAÇÃO E MEMÓRIA DO ATHENEU SERGIPENSE
}

\author{
Eva Maria Siqueira Alves \\ Universidade Federal de Sergipe/Departamento de Educação \\ evasa@uol.com.br
}

\section{RESUMO}

O foco central do presente trabalho consiste em expor as diversas fases e ações da edificação do Centro de Educação e Memória do Atheneu Sergipense - CEMAS, visando responder as questões: o que um arquivo escolar produz? Que tipo de documentos e em qual local estão "guardados"? A divisão metodológica inicia pelo momento anterior à sua criação, passando pelo período de mais intensos afazeres com a identificação, limpeza e catalogação do acervo, a etapa de disseminação das ações com a produção científica, a fase atual com parte do acervo digitalizada e a produção dos guias de fontes, até a projeção futura de novas atuações. As vozes silenciadas da memória educacional sergipana começaram a falar...

Palavras-chave: Centro de Memória. Atheneu Sergipense. Arquivo. História da Educação. Sergipe.

\section{THE EDIFICATION OF THE CENTRO DE EDUCAÇÃO E MEMÓRIA DO ATHENEU SERGIPENSE}

\begin{abstract}
The main focus of this work is to expose the different phases and actions in the edification of the Centro de Educação e Memória do Atheneu Sergipense - CEMAS, in order to answer the questions: What a school file produces? What kind of documents and where are they "kept"? The methodological division starts from the moment prior to its creation, passing through the period with intense tasks, identifying, cleaning and cataloguing the collection, the dissemination stage of the actions with scientific production, the current phase with part of the collection digitized and production of source guides, to the future projection of new performances. The silenced voices of Sergipe educational memory began to speak...
\end{abstract}

Keywords: Memory Center. Atheneu Sergipense. File. History of Education. Sergipe.

\section{LA EDIFICACIÓN DEL CENTRO DE EDUCACIÓN Y MEMORIA DEL ATHENEU SERGIPENSE}

\section{RESUMEN}

El eje central de este trabajo es exponer las distintas etapas y acciones de la edificación del Centro de Educación y Memoria del Atheneu Sergipense - CEMAS, con el fin de responder a las preguntas: ¿qué produce un archivo de la escuela? ¿Qué tipo de documentos y qué lugar están "guardados"? La división metodológica comienza en el momento anterior a su creación, a través del período de más intensos quehaceres con la identificación, limpieza y catalogación del acervo, la fase de difusión de las acciones con la producción científica, la fase actual de 
parte del acervo digitalizado y la producción de los guías de las fuentes a la proyección futura de nuevas actuaciones. Las voces silenciadas de la memoria educativa de Sergipe comenzaron a hablar...

Palabras clave: Centro de Memoria. Atheneu Sergipense. Archivo. Historia de la Educación. Sergipe.

\section{O EMARANHADO DE PAPÉIS}

Declaro: nunca havia ingressado em um arquivo; as minhas atividades até então não necessitavam desse investimento. Mas enfim chegou o dia. Em setembro de 2001, quando iniciava o doutorado realizado na Pontifícia Universidade Católica de São Paulo, adentrei no "arquivo" do Atheneu Sergipense e deparei-me com um emaranhado de papéis sem qualquer organização e acondicionamento, localizados na "sala da banda marcial". Era uma sala na parte superior da escola, medindo aproximadamente $3 \mathrm{~m} \times 2 \mathrm{~m}$, com estantes de ferro, onde estavam cuidadosamente organizados os instrumentos musicais da banda escolar. A predileção naquele espaço era semelhante à do Diretor Aristarco do Atheneu de Raul Pompéia. Havia também um armário de ferro com as cadernetas e diários dos professores. E os "papéis velhos"? Estes estavam jogados, amontoados em um banheiro desativado, anexo à sala (figura 1). Duas estantes de ferro, em estado mais deteriorado que a dos instrumentos musicais, uma quinquilharia de objetos misturados, vassoura, papelão, cartazes de isopor, a poeira do tempo...

Fotografei o local, "espanejando a poeira que testemunha sua antiguidade e seu abandono pelos homens [...] e ouvindo 'cuidado, tem gente aqui!'” (SLENES, 1985, p. 173), privilegiei os apontamentos do período que necessitava estudar, porém observei a riqueza de documentos de outros anos, que certamente subsidiaria futuros trabalhos de investigação histórica. Ali estava a história erguida pelo Atheneu Sergipense, com o patrimônio do arquivo corrente e também com a documentação histórica ainda existente no espaço que alguns consideram erroneamente como "arquivo morto", necessários de organização e preservação. A situação deparada não era das melhores: vários livros apresentavam-se em deterioração progressiva, descuidados, relegados a condições insalubres de conservação. Vi "papéis" do passado, fontes necessárias àquele estudo do presente, mas já projetava pesquisas futuras. 
Figura 1: Documentação histórica do Atheneu Sergipense, 2001.

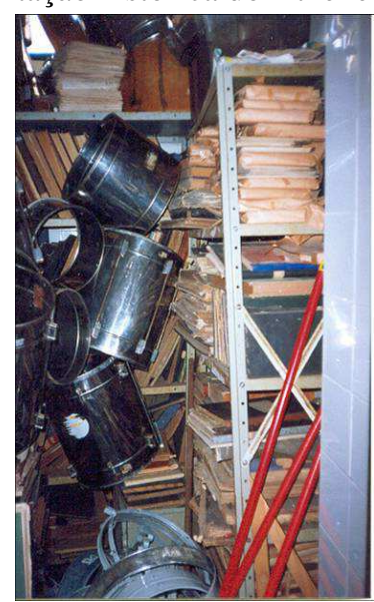

Fonte: Acervo do CEMAS.

Mesmo o Atheneu Sergipense não preservando uma organização satisfatória do arquivo até aquele momento, Santana (2012) identificou que esse tema constituía uma preocupação constante dos dirigentes da instituição, desde os primeiros vestígios do ensino secundário no Liceu de Sergipe nos anos de 1849 e estabelece uma relação com as práticas administrativas. Ressalta ainda para os cuidados, atenção e queixas dos administradores expressos nos "relatórios" para com a "conservação dos papéis produzidos". Tomando como fonte prioritária os relatórios, declara que estes "são a tipologia documental que apresenta mais dados em relação ao funcionamento da instituição, mostrando uma visão específica dos diversos setores que a compunham" (SANTANA, 2012, p. 86).

Prosseguindo a pesquisa, Santana (2012) identifica representações peculiares dos agentes escolares, especificamente desde o ano de 1849 no Liceu de Sergipe, a respeito da noção do que para eles constituía-se um arquivo e destaca um ofício do Diretor José Gonçalves Barroso que solicita ao Presidente da Província a aquisição de um "archivo para a boa guarda dos livros, e mais papeis do Lyceu". Nas diversas denominações e lugares de instalação da escola, há o cuidado das direções pela guarda dos papéis administrativos.

Mas como essa organização do arquivo histórico do Atheneu Sergipense se processou?

\section{A CRIAÇÃO DO CEMAS}

Concluído o doutorado e não satisfeita com os locais de armazenamento e não organização dos documentos históricos do Atheneu Sergipense visitei o "Centro de Memória da Educação" da USP, de modo a conhecer as atividades realizadas quanto a preservação e 
aparelhamento de acervos escolares. Instigada pelo que observei e convicta que devia dar um retorno à comunidade daquela escola que, mesmo guardando o emaranhado de "papéis velhos" em péssimo estado de conservação, permitiu que utilizasse uma massa documental que em tão alto grau serviu para o êxito da minha pesquisa, urgia fazer algo para organizar tal acervo.

Apresentei então no ano de 2005, o projeto "Centro de Educação e Memória do Atheneu Sergipense - CEMAS" à Fundação de Apoio à Pesquisa e à Inovação Tecnológica do Estado de Sergipe - FAPITEC (naquele ano denominada FAP/SE), que, após sua aprovação, financiou a exposição comemorativa dos 135 anos do Atheneu Sergipense. A semente germinada fez brotar o CEMAS, com o objetivo de salvaguardar as fontes históricas do Atheneu Sergipense, parte significativa da história da educação de Sergipe.

Mas a maior motivação para a organização de um centro de memória dentro de uma instituição, declara Zaia (2005), é reunir documentos de diferentes suportes, formatos e tipos documentais, recolhidos no "arquivo morto" da escola e/ou recebidos através de doações e permuta. Além dessa autora, as palavras de Ragazzini (2001) incentivam a organização de arquivos, ao considerar que

[...] é de grande importância o desenvolvimento de uma consciência e de uma prática documentária de individualização, catalogação e conservação dos documentos. As novas identidades da História da Educação foram muito discutidas, assim como as possibilidades de uma aproximação inovadora com a história da escola, contudo, enquanto permanecemos sem uma prática de documentação adequada, permaneceremos no âmbito das discussões acadêmicas ou do pioneirismo. Uma historiografia mais sofisticada requer uma inovação no uso das fontes e isto não será possível sem uma nova prática de pesquisa, uma nova prática arquivista e uma nova sensibilidade documentária (RAGAZZINI, 2001, p. 26).

De modo a efetivamente desenvolver uma prática de pesquisa arquivista com a sensibilidade de proteger os documentos valiosos da escola, instituiu-se o CEMAS e a primeira ação desenvolvida foi a realização da exposição comemorativa dos 135 anos do Atheneu Sergipense. O Atheneu Sergipense, estabelecimento oficial de estudos secundários de Sergipe criado a 24 de outubro de 1870, durante o Governo de Francisco José Cardoso Júnior, quando a cidade de Inácio Joaquim Barbosa (Aracaju) completava quinze anos, ofereceu inicialmente os cursos de Humanidades, com quatro anos de duração e o Normal, feito em dois anos.

$\mathrm{Na}$ entrada da exposição o visitante contemplou um amplo mapa localizando os diferentes espaços de instalação do Atheneu Sergipense. Compondo as peças documentais do 
primeiro módulo, esteve exposto o primeiro livro de Atas da Congregação (1871 a 1916), o livro comemorativo do $1^{\circ}$ centenário da escola e um livro de correspondências do Liceu de São Cristóvão, datado do ano de 1848. O $2^{\circ}$ módulo denominado "O Corpo Discente: ânima da escola" retratou os alunos, a vida, a alma. Ser aluno do Atheneu Sergipense constituía-se orgulho daqueles que lá ingressavam após rigoroso processo seletivo. Compuseram a coleção desse módulo símbolos que retratavam a vida discente daqueles que buscavam enrijecer as asas para os grandes voos: livros, cadernos, cadernetas, fardas, livro de punições. Os objetos escolares foram cedidos por ex-alunos que, ao observarem a exposição, transportavam-se aos tempos mágicos do colégio, às brincadeiras, aos namoricos, às farras às escondidas, e tudo isso aflorava num arrepio quando a sirene tocava, num olho cheio de lágrimas ao ver sua antiga farda ou até sua velha fotografia exposta (ALVES et al., 2008). O $3^{\circ}$ módulo, intitulado "A Douta Congregação", retratou o corpo docente, os professores, os diretores. As peças selecionadas pela comissão organizadora para esse módulo foram: cadernetas de professores, um dos regulamentos do Atheneu Sergipense, instrumentos dos laboratórios e teses que os professores apresentavam ao prestarem concursos para ingressarem na escola.

Era apenas o início das ações do CEMAS. Cabe destacar que desde então, distintas agências de fomento, por meio de seus Editais, disponibilizaram recursos para as investigações: Universidade Federal de Sergipe; Fundação de Apoio à Pesquisa e à Inovação Tecnológica do Estado de Sergipe (FAPITEC); Fundação de Apoio à Universidade Federal de São João Del Rey, patrocinado pela PETROBRÁS e realizado pelos Ministérios da Cultura e da Educação do Governo Federal e agregado a PROEX/UFS; CNPq. As pesquisas financiadas incluíram em suas equipes, alunos bolsistas do Programa de Iniciação Científica Júnior (PIBICJ/CNPq/FAPITEC), Programa de Iniciação Científica (PIBIC/UFS), Programa de Incentivo à Iniciação Científica (PIIC/UFS), Programa Institucional de Bolsas de Iniciação à Extensão (PIBIX), alunos do Mestrado e do Doutorado em Educação da UFS. Esse conjunto de instituições possibilitou a participação de atores que não mediram esforços para organizar a massa documental histórica do Atheneu Sergipense e salvaguardá-la no CEMAS.

\section{COM AS MÃOS SUJAS}

Mas o que são arquivos escolares?

Os arquivos escolares constituem o repositório das fontes de informação directamente relacionadas com o funcionamento das instituições educativas, o que 
lhes confere uma importância acrescida nos novos caminhos da investigação em educação, que colocam estas instituições numa posição de grande centralidade para a compreensão dos fenômenos educativos e dos processos de socialização das gerações mais jovens. (MOGARRO, 2005, p. 76).

As afirmações de Mogarro (2005) complementam os dizeres de Belloto (2002) ao concluir que:

\begin{abstract}
Documentos de arquivo são testemunhos inequívocos da vida de uma instituição. Informações sobre o estabelecimento, a competência, as atribuições, as funções, as operações e as atuações levadas a efeito, por uma entidade pública ou privada, no decorrer de sua existência, estão registradas nos arquivos. De outro lado, também demonstram como decorrem - e decorreram - as relações administrativas, políticas e sociais por ela mantidas, tanto no âmbito interno como no externo, sejam com outras entidades de seu mesmo nível, ou com as que lhe são, hierarquicamente, superiores ou inferiores. (BELLOTO, 2002, p. 9).
\end{abstract}

Os documentos do Atheneu Sergipense são diversos, dispersos e extensos, decorrentes de suas atividades tanto administrativas como pedagógicas, que testemunham a vida daquela "Casa de Educação Literária” (ALVES, 2005). E para iniciar a organização dos "papéis emaranhados" era preciso "sujar as mãos" do pó das luvas, material necessário para a limpeza dos documentos. A metragem inicial encontrada no arquivo do Atheneu Sergipense media 71 metros, ficando dividido em 19 metros de documentação catalogada e 52 metros de material posterior ao período de 1950 (inicialmente a catalogação atendeu ao período de 1848 a 1850). A fase de higienização e o acondicionamento dos documentos são processos fundamentais, embora trabalhosos e morosos, para a preservação do acervo de modo a mantê-lo em estado de uso. Para inventariar o conjunto documental foi elaborada uma ficha de identificação contendo os itens: Título do Documento; Data / Período; Autor; Dimensão; Tipo (transcrição / original); Suporte / Formato; Conteúdo; Número de Folhas; Observações.

Organizar é construir uma ordem. O exercício de organização do arquivo histórico do Atheneu Sergipense amparou-se em autores como Bacellar (2008), Belloto (2002, 2004), Moraes (2002, 2005) e Zaia $(2004,2005)$, com um procedimento metodológico de cunho historiográfico e a documentação foi pouco a pouco sendo separada e armazenada em caixas com identificação de fundo, série e notação. Compõem o acervo do CEMAS as séries: Atas, Atestados Médicos, Boletins, Cadernetas, Correspondências, Exames e Concursos, Imprensa, Livros de Ponto, Livros de Registros, Matrículas e Transferências, e duas subséries: Correspondências Expedidas e Recebidas.

Retirada a poeira desse conjunto de documentos escritos, após um longo processo de limpeza e catalogação, materialmente, cada documento foi acondicionado em pacotes, com 
numeração específica, sendo distribuídos de acordo com a série documental em mais de 200 caixas-arquivo, contendo cerca de 90.000 páginas em distintos estados de conservação. A documentação mais deteriorada passou por processo de digitalização e arquivamento digital (em torno de 8.000 páginas), compondo o volume 1 do CD-ROM de Acervo Digital do CEMAS. Fazem parte também desse CD algumas produções científicas cujos autores utilizaram como fonte de pesquisa o acervo do CEMAS.

Segundo Bellotto (2004), "arranjo", na linguagem da arquivista, é o processo de organização intelectual e material de arquivos e seguindo tal preceito, o acervo documental do CEMAS está organizado em um único Fundo denominado Atheneu Sergipense, dentro do período de 1848 a 1970, que expressam elementos administrativos e pedagógicos da instituição secundária.

Figura 2: Documentação histórica do Atheneu Sergipense, 2015.

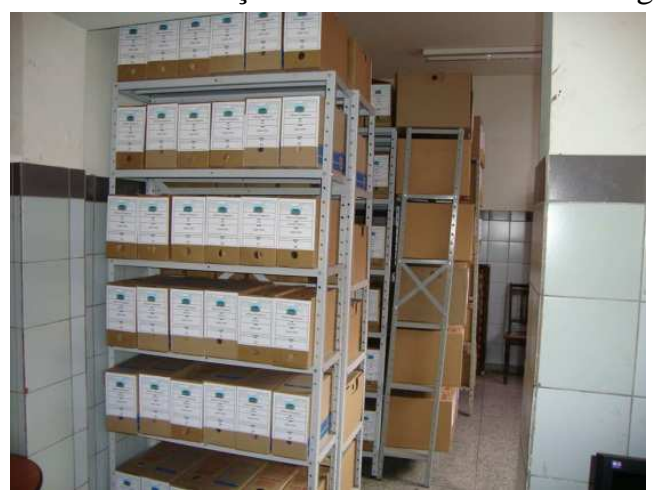

Fonte: Acervo do CEMAS.

Após essa organização, não mais "sujando as mãos", foram elaborados seis livros nomeados "Guia de Fontes". Dois livros abrangem o período de 1848 a 1950, identificando os documentos subdivididos em dez séries (Atas, Atestados Médicos, Boletins, Cadernetas, Correspondências, Exames e Concursos, Imprensa, Livros de Ponto, Livros de Registros, Matrículas e Transferências), e duas subséries (Correspondências Expedidas e Recebidas). Outros dois livros "Guia de Fontes", compreendendo o período de 1950 a 1970, apresentam a mesma divisão que o anterior. Há também o "Guia de Fontes da Arcádia Literária Estudantil do Atheneu Sergipense", que identifica os documentos dessa agremiação estudantil, subdividido nas séries: Concursos de Poesia, Correspondências, Documentos Oficiais, Ficha dos Sócios, Imprensa, Livros de Atas, Livros de Registros, Livros e Desenhos, Monografias para Concursos da Arcádia, Poesias, Panfletos, Cartazes. Por fim, o livro "Guia de Fontes 
Iconográficas" que cataloga as fotografias relacionadas ao Atheneu Sergipense e localizadas no Instituto Histórico e Geográfico de Sergipe, que revelam professores em excursões, aulas práticas, laboratórios, reuniões. Está em construção o "Guia de Fontes da Memória do CEMAS" que narra a vida do próprio centro de memória, contendo fotografias que ilustram momentos do CEMAS como eventos, visitas, ações de trabalho. Completam o acervo quadros, troféus, móveis e livros que os árcades recebiam por doação.

Esse conjunto de múltiplas informações reflete a "própria multidimensionalidade e complexidade das realidades escolares e formativas, assim como a diversidade e pluralidade dos meios de intervenção dos agentes educativos" (MOGARRO, 2005, p 83). Fato é que a hodierna organização dos documentos históricos do Atheneu Sergipense consente que permaneçam no local que os produziu não mais sendo "desviados" para arquivos pessoais, queimados ou descartados. É a massa acumulada que persistiu em não desaparecer do Atheneu Sergipense (ALVES, 2008).

\title{
E AS VOZES SILENCIADAS COMEÇARAM A FALAR...
}

\begin{abstract}
As fontes não falam per se. São vestígios, testemunhas que respondem - como podem e por um número limitado de fatos - às perguntas que lhe são apresentadas. A fonte é uma construção do pesquisador, isto é, um reconhecimento que se constitui em uma denominação e em uma atribuição de sentido; é uma parte da operação historiográfica. [...] A fonte é uma ponte, um veículo, uma testemunha, um lugar de verificação, um elemento capaz de propiciar conhecimentos acertados sobre o passado.

As fontes permitem encontrar e reconhecer: encontrar materialmente e reconhecer culturalmente a intencionalidade inerente ao seu processo de produção. Para encontrar é necessário procurar e estar disponível ao encontro: não basta olhar, é necessário ver. Para reconhecer é necessário atribuir significado, isto é, ler e indicar os signos e os vestígios como sinais. (RAGAZZINI, 2001, p. 14).
\end{abstract}

Encontrada a documentação histórica do Atheneu Sergipense no CEMAS, o Grupo de Pesquisa Disciplinas Escolares: História, Ensino, Aprendizagem - DEHEA (UFS/CNPq) tem reconhecido e dado significado àquelas fontes, dedicando-se às investigações sobre temáticas como: História das Disciplinas, Livros Didáticos, Formação dos Professores do Ensino Secundário, Intelectuais, Agremiações Estudantis, Jornais Estudantis, Legislação Educacional, Concursos, Sistema de Avaliação, dentre outros frutíferos temas, ampliando e renovando sobremaneira a produção acadêmica.

Dois quadros merecem destaque de modo a expor as produções realizadas que tomaram como fontes documentos do CEMAS. Estão listados no quadro 1 os projetos de pesquisas por mim coordenados e no quadro 2 as teses, dissertações, monografias que 
também receberam a minha orientação. Além desses, há outras produções como livros, capítulos de livros, artigos, trabalhos em eventos, que utilizaram as fontes do CEMAS com orientações de diferentes pesquisadores.

Quadro 1 - Pesquisas realizadas com a documentação do CEMAS.

\begin{tabular}{|c|c|c|c|}
\hline ANO & TÍTULO & AGÊNCIA & EQUIPE \\
\hline 2014 & $\begin{array}{c}\text { Organização de arquivos escolares: da teoria à } \\
\text { prática }\end{array}$ & PROEX/UFS & $2 \mathrm{G} ; 3 \mathrm{M} ; 4 \mathrm{D}$ \\
\hline 2013 & $\begin{array}{l}\text { O Atheneu Sergipense: um lugar de memória } \\
\text { da educação }\end{array}$ & PROEX/UFS & 4G; 1M; 3D \\
\hline 2011-2014 & $\begin{array}{l}\text { Uma história das disciplinas escolares: os } \\
\text { conteúdos dos planos de estudos na } \\
\text { configuração do ensino secundário de Sergipe } \\
\text { no final do século XIX e início do século XX }\end{array}$ & $\mathrm{CNPq}$ & 1G; 3M; 4D \\
\hline $2011-2012$ & $\begin{array}{l}\text { Uma história da disciplina Pedagogia do Curso } \\
\text { Normal do Atheneu Sergipense (1870-1901) }\end{array}$ & CNPq e UFS & $3 \mathrm{G} ; 1 \mathrm{D}$ \\
\hline $2010-2011$ & $\begin{array}{l}\text { A história das disciplinas escolares no Atheneu } \\
\text { Sergipense: traços característicos de uma } \\
\text { história }\end{array}$ & FAPITEC & $\begin{array}{l}\text { 2EM; 2G; } \\
6 \mathrm{M} ; 2 \mathrm{D}\end{array}$ \\
\hline 2009 & $\begin{array}{l}\text { Centro de Educação e Memória do Atheneu } \\
\text { Sergipense }\end{array}$ & MEC/CULTURA & $6 \mathrm{G} ; 5 \mathrm{M}$ \\
\hline $2007-2008$ & $\begin{array}{c}\text { Professores de Matemática do Atheneu } \\
\text { Sergipense (1870-1931) }\end{array}$ & FAPITEC/SE & $1 \mathrm{G}$ \\
\hline $2005-2007$ & $\begin{array}{c}\text { Centro de Educação e Memória do Atheneu } \\
\text { Sergipense }\end{array}$ & FAPITEC/SE & $6 \mathrm{EM} ; 2 \mathrm{G}$ \\
\hline 2003-2004 & $\begin{array}{c}\text { Prêmios e sanções como elementos } \\
\text { característicos da cultura escolar no Atheneu } \\
\text { Sergipense }\end{array}$ & FAPITEC/SE & 2EM; $1 \mathrm{G}$ \\
\hline
\end{tabular}

Fonte: ALVES, 2015, p. 31.

Legenda: EM (alunos do Ensino Médio); G (alunos da Graduação); M (alunos do Mestrado); D (alunos do Doutorado). 
Quadro 2 - Teses, Dissertações, Monografias.

\begin{tabular}{|c|c|c|c|}
\hline TÍTULO & AUTOR & TIPO & ANO \\
\hline $\begin{array}{c}\text { Com a palavra "Os Alunos": associativismo } \\
\text { discente no Grêmio Literário Clodomir Silva } \\
(1934 \text { - 1956) }\end{array}$ & Simone Paixão Rodrigues & Tese & 2015 \\
\hline $\begin{array}{l}\text { Caminhos cruzados: itinerários de professores } \\
\text { do Ensino Superior sergipano (1915-1954) }\end{array}$ & João Paulo Gama Oliveira & Tese & 2015 \\
\hline $\begin{array}{c}\text { Apresentais os fatos, ensinais a efetuar o } \\
\text { mundo: as Cartas de Parker em Sergipe (1912- } \\
\text { 1953). }\end{array}$ & Adriana Menezes de Santana & Dissertação & 2015 \\
\hline $\begin{array}{c}\text { A Geografia e uma história: a disciplina de } \\
\text { Geografia no Atheneu Sergipense entre os anos } \\
\text { de } 1870 \text { e } 1908\end{array}$ & André Luis Conceição Alves & Dissertação & 2014 \\
\hline $\begin{array}{c}\text { Elite letrada e ofício docente em Sergipe no } \\
\text { século XIX }\end{array}$ & Fábio Alves dos Santos & Tese & 2013 \\
\hline $\begin{array}{c}\text { Ignácio de Souza Valladão: traços do precursor } \\
\text { da cadeira de Pedagogia do Curso Normal do } \\
\text { Atheneu Sergipense (1855-1884) }\end{array}$ & Cibele de Souza Rodrigues & Monografia & 2013 \\
\hline $\begin{array}{l}\text { A Escola Normal do Atheneu Sergipense } \\
\text { durante a ação do Regulamento de } 1874\end{array}$ & Maria Edna Santos & Monografia & 2013 \\
\hline $\begin{array}{l}\text { Do ponto à forma: a disciplina desenho no } \\
\text { Atheneu Sergipense (1905-1930) }\end{array}$ & $\begin{array}{l}\text { Daniellle Virginie Santos } \\
\text { Guimarães }\end{array}$ & Dissertação & 2012 \\
\hline $\begin{array}{c}\text { "Amai a Pátria": o ensino da disciplina } \\
\text { Educação Moral e Cívica no Atheneu } \\
\text { Sergipense (Década de } 70 \text { do século XX) }\end{array}$ & Patricia Batista dos Santos & Dissertação & 2012 \\
\hline $\begin{array}{c}\text { Por entre memórias de uma instituição: o } \\
\text { arquivo escolar do Atheneu Sergipense (1870- } \\
1926)\end{array}$ & $\begin{array}{l}\text { Sayonara Rodrigues do } \\
\text { Nascimento }\end{array}$ & Dissertação & 2012 \\
\hline $\begin{array}{c}\text { Uma História da Disciplina Matemática no } \\
\text { Atheneu Sergipense durante a ação da Reforma } \\
\text { Francisco Campos (1938-1943) }\end{array}$ & Suely Cristina Silva Souza & Dissertação & 2011 \\
\hline $\begin{array}{c}\text { Disciplinas, Docentes e Conteúdos: itinerários } \\
\text { da História na Faculdade Católica de Filosofia } \\
\text { de Sergipe (1951-1962) }\end{array}$ & João Paulo Gama Oliveira & Dissertação & 2011 \\
\hline $\begin{array}{c}\text { Sob a lente do discurso: aspectos do ensino de } \\
\text { Retórica e Poética no Atheneu Sergipense } \\
(1874-1891)\end{array}$ & Ana Marcia Barbosa dos Santos & Dissertação & 2010 \\
\hline $\begin{array}{l}\text { O Necydalus: um jornal estudantil do Atheneu } \\
\text { Sergipense (1909-1911) }\end{array}$ & $\begin{array}{c}\text { Valdevania Freitas dos Santos } \\
\text { Vidal }\end{array}$ & Dissertação & 2009 \\
\hline $\begin{array}{c}\text { Economia Doméstica no Atheneu Sergipense: } \\
\text { uma análise da disciplina entre os anos de } 1944 \\
\text { e } 1949\end{array}$ & Iara Alves de Farias & Monografia & 2009 \\
\hline $\begin{array}{l}\text { Artes no ensino secundário: o aprendizado do } \\
\text { Desenho no Atheneu Sergipense: } 1889 \text { a } 1908\end{array}$ & Manoel Odilon Farias Pereira & $\begin{array}{l}\text { Especializaçã } \\
\text { o } \\
\end{array}$ & 2008 \\
\hline $\begin{array}{l}\text { O Curso de História e Geografia da Faculdade } \\
\text { Católica de Filosofia de Sergipe }\end{array}$ & João Paulo Gama de Oliveira & Monografia & 2008 \\
\hline $\begin{array}{l}\text { Concursos para Professores do Atheneu } \\
\text { Sergipense: a Cadeira de História }\end{array}$ & Igor Pereira Teles & Monografia & 2008 \\
\hline $\begin{array}{c}\text { A Reforma Gustavo Capanema: vislumbrada } \\
\text { no currículo do Atheneu Sergipense (1940- } \\
1944) \\
\end{array}$ & $\begin{array}{l}\text { Sayonara do Espírito Santo } \\
\text { Almeida }\end{array}$ & Monografia & 2008 \\
\hline $\begin{array}{c}\text { A Arte na Educação Basileira: o ensino do } \\
\text { Desenho no Atheneu Sergipense de } 1899 \text { a } \\
1906\end{array}$ & Manuel Odilon Farias Pereira & Monografia & 2006 \\
\hline
\end{tabular}

Fonte: Quadro organizado a partir do Currículo Lattes/CNPq da autora. 
Se a análise focasse apenas na produção acadêmica que tomou como fontes os documentos do CEMAS e destacados nos quadros anteriores, já teria valido a pena todo o investimento realizado, o susto diante dos papéis emaranhados, as mãos sujas. São as vozes silenciadas que começaram a falar...

Porém esses não constituíram os únicos frutos gerados. Quatro seminários ocorridos nos anos de 2012, 2013, 2014 e 2015 foram realizados, objetivando transmitir para a comunidade escolar, traços da história do secular Atheneu Sergipense. O penúltimo deles, intitulado "O Atheneu Sergipense narra sua história" promoveu uma visita guiada, um tour histórico, percorrendo locais emblemáticos como a entrada do prédio, a galeria de diretores, os laboratórios de química, física e biologia, a biblioteca, o grêmio estudantil, a sala da banda e terminando o percurso no CEMAS. Em cada um desses espaços, alunos e professores ouviam atentos aspectos históricos da sua escola, que para alguns era novidade, acostumados que estavam de passar e frequentar todos aqueles ambientes, sem despertar o interesse em conhecê-los, em saber dos traços históricos que constituiu a secular escola Atheneu Sergipense.

O acúmulo de conhecimentos da equipe envolvida nas ações do CEMAS não devia ser "arquivado", necessitava sim, ser divulgado e expandido após 10 anos de sua criação. Assim elaboramos e executamos com aprovação pela Pró-reitoria de Extensão e Assuntos Comunitários da UFS o projeto "Organização de arquivos escolares: da teoria à prática" com o objetivo de divulgar/popularizar/expandir os saberes adquiridos, promovendo cursos de formação para 5 escolas pertencentes à Rede Estadual de Ensino, abordando os conteúdos da legislação pertinente à preservação dos documentos, os conceitos e princípios da arquivologia, além do acompanhamento na consolidação da organização desses acervos escolares.

Consequentemente, a proposta estabeleceu uma estreita relação com atividades de ensino, pesquisa e extensão. Contribuiu sobremaneira com a difusão do conhecimento científico e experiência acumulada uma vez que envolveu a comunidade acadêmica (professores, alunos da graduação, mestrandos, doutorandos), a comunidade das instituições envolvidas (direção, professores, técnicos, alunos), da Secretaria de Estado da Educação, da Secretaria de Cultura, do Instituto Histórico e Geográfico de Sergipe, da sociedade organizada, todos com o objetivo de salvaguardar o patrimônio cultural da memória educacional e social das instituições educacionais do Estado de Sergipe. 
As escolas estaduais Atheneu Sergipense, Tobias Barreto, Presidente Costa e Silva, Manoel Luiz, Petrônio Portela, selecionadas dentro do critério de serem algumas das mais antigas da rede, foram visitadas pela equipe para expor a proposta e receber a autorização da diretoria para participar do projeto.

O curso dividido em módulos buscou no primeiro momento levar ao conhecimento dos cursistas os seguintes aspectos: a proposta do curso (objetivos e cronogramas das atividades); a equipe que compõe a pesquisa; o Centro de Educação e Memória do Atheneu Sergipense (CEMAS) e os resultados obtidos; os conceitos e tipos de arquivos; leitura de um texto sobre Arquivos escolares; e ainda o levantamento da situação dos arquivos das escolas participantes.

No módulo seguinte o foco esteve voltado para esclarecer aos cursistas a prática da teoria que lhes foi apresentada durante o primeiro módulo. Para tanto, o grupo foi dividido para que pudéssemos melhor demonstrar a forma como está organizado o acervo do CEMAS, além de realizar atividades práticas de higienização, empacotamento, identificação e organização dos documentos.

O módulo três, correspondeu à parte inicial da prática da organização dos arquivos das escolas contempladas pelo projeto e com a supervisão e acompanhamento da equipe do CEMAS. Objetivando atender as necessidades dos funcionários de cada escola, uma vez que estes (a maioria) não possuem noção alguma de preservação documental, a tarefa foi executada em cada uma das escolas para dar inicio a organização dos seus arquivos.

No último módulo, a ação constou de um seminário em que as escolas participantes do projeto, ou seja, os responsáveis pelos arquivos dessas escolas, apresentaram os resultados que obtiveram ao longo do processo de higienização, empacotamento, catalogação e armazenamento dos documentos provenientes das respectivas instituições escolares.

A frequência de diretores, secretários, outros professores interessados, além de alunos dos cursos de Pedagogia e Biblioteconomia da Universidade Federal de Sergipe pode ser considerada um aspecto positivo. Cabe destacar que o referido projeto está aprovado pela PróReitoria de Extensão da UFS para ser executado no ano de 2016 com essas e/ou outras escolas.

Considero por fim que a culminância dos investimentos alocados no CEMAS se expressa por meio do "Termo de Convênio de Cooperação Técnica assinado entre a Universidade Federal de Sergipe e a Secretaria de Estado da Educação", número 1912.020/2013, com o 
objetivo de executar atividades de pesquisa, ensino e extensão no âmbito do Centro de Educação e Memória do Atheneu Sergipense. Com esse termo, o CEMAS é oficialmente institucionalizado.

\section{PROJEÇÕES DO CEMAS}

O CEMAS tem por principal objetivo preservar os vestígios escritos ou não, o testemunho histórico, além de criar informações necessárias para salvaguardar o patrimônio cultural e manter exposição permanente da memória educacional e social do Atheneu Sergipense, da instituição que desempenhou papel relevante como agência produtora e irradiadora de práticas e padrões pedagógicos, projetando vultos de destaque no panorama político e social, considerada como parte significativa da História da Educação do Estado de Sergipe.

Nesse percurso, projeções devem ser feitas, outras propostas de ações planejadas, a saber: completar a digitalização do acervo; construir página virtual ou abrigar o arquivo em página da Secretaria de Educação; organizar exposições temporárias da história da instituição; receber, por doação, materiais de ex-alunos, professores e funcionários; executar o curso de arquivos escolares para outras instituições escolares, além de prosseguir com a produção científica, permitindo que os escritos nos emaranhados de papéis continuem a falar.

Concluo almejando que o Centro de Educação e Memória do Atheneu Sergipense CEMAS aqui exposto incentive instituições públicas e privadas a valorizarem sua história, preservando os vestígios de seu passado e consequentemente salvaguardando o patrimônio cultural, social e educacional brasileiro.

\section{REFERÊNCIAS}

ALVES, Eva Maria Siqueira. Entre papéis e lembranças: o Centro de Educação e Memória do Atheneu Sergipense e as contribuições para a história da educação. Aracaju: FAPITEC/SEGRASE, 2015.

O Atheneu Sergipense: Uma Casa de Educação Literária, examinada segundo os planos de estudos (1870-1908). Tese - Pontifícia Universidade Católica de São Paulo, São Paulo, 2005.

ALVES, Eva Maria Siqueira; OLIVEIRA, João Paulo Gama; TELES, Igor Pereira. O Centro de Educação e Memória do Atheneu Sergipense: Contribuições para a História da Educação. Revista da FAPESE, Aracaju-SE, vol. 4, n. 1, p.79-88, 2008. 
BACELLAR, Carlos. Uso e mau uso dos arquivos. In: PINSKY, Carla Bassanezi (Org.). Fontes históricas. São Paulo: Contexto, 2008, p.23-79.

BELLOTO, Heloísa Liberalli. Arquivos permanentes - tratamento documental. 2. ed. Rio de Janeiro: Editora FGV, 2004.

BELLOTO, Heloísa Liberalli. Inventário dos acervos das Escolas Técnicas estaduais de São Paulo. In: MORAES, Carmem Sylvia Vidigal; ALVES, Júlia Falivene (Orgs.). Contribuições para a pesquisa do ensino técnico em São Paulo: inventário de fontes documentais. Centro Paula Souza, 2002, p.22-35.

MORAES, Carmem Sylvia Vidigal; ALVES, Julia Falivene (Orgs.). Contribuição para a pesquisa do ensino técnico em São Paulo: inventário de fontes documentais. Centro Paula Souza, 2002.

MORAES, Carmem Sylvia Vidigal; ZAIA, Iomar Barbosa; VENDRAMETO, Maria Cristina. Arquivos escolares e pesquisa histórica: fontes para o estudo da educação brasileira. In: ProPosições - Dossiê Cultura escolar e cultura material escolar: entre arquivos e museus, Revista da Faculdade de Educação da UNICAMP, Campinas, v.16, n.I(46), jan./abr. 2005.

MOGARRO, Maria João. Arquivos e educação. Revista Brasileira de História da Educação. Campinas/SP. v.5 - n.2 [10], p. 75-99, jul./dez. 2005.

RAGAZZINI, Dario. Para quem e o que testemunham as fontes da História da Educação? Educar em Revista, Curitiba, UFPR, n.18, p.13-28, 2001.

SANTANA, Sayonara Rodrigues do Nascimento. Por entre as memórias de uma instituição: o arquivo e as práticas administrativas do Atheneu Sergipense (1870-1926). 159f. Dissertação (Mestrado em Educação) - Universidade Federal de Sergipe, São Cristóvão, 2012.

SLENES, Robert W. Escravos, cartórios e desburocratização: o que Rui Barbosa não queimou será destruído agora? Revista Brasileira de História. São Paulo, v.5, n. 10, p.166-196, mar./ago.1985.

ZAIA, Iomar Barbosa. O lugar do arquivo permanente dentro de um centro de memória escolar. Revista Brasileira de História da Educação. Campinas/SP. v.5 - n.2 [10], p. 153171, jul./dez. 2005.

O acervo escolar: organização e cuidados básicos. FEUSP, São Paulo, 2004. 